\title{
IMPLEMENTASI TEKNOLOGI COMPUTER VISION SEBAGAI PENGENDALI MOBILE ROBOT BERBASIS KAMERA WEB
}

\author{
Samsul Arifin ${ }^{1)}$, Erwien Tjipta Wijaya ${ }^{2)}$ \\ ${ }^{1,2)}$ STMIK Asia Malang \\ Email: $\underline{\text { s4ms.s0ul@gmail.com }}{ }^{1)}$, erwin.cipta@ gmail.com ${ }^{2)}$
}

\begin{abstract}
In this research will be developed autonomous Mobile Robot navigation system, using vision sensor in the form of web camera. The ability of the robot to find the path, avoiding obstacles in an indoor environment becomes the key to the success of navigation. One of the things that underlies the robot navigation system is the process of image information processing from a web camera. So it takes a method that can process image information from the web camera into image data more easily read by the computer. The method that can be used to solve this problem is Canny Edge Detection. Canny Edge Detection has some of the most optimum edge detection criteria that localize the image well, detect objects well and clear response. With these advantages, the Canny Edge Detection method can produce a more representative image approaching the real object. After the edge detection process is completed then the next step is to identify and identify paths or obstacles that exist. Paths and obstructions that have been identified will be used as models to determine which direction the robot will run. The whole process of computing and control will be done using Raspberry pi, while for image processing using OpenCV application.
\end{abstract}

Keywords: Canny Edge Detection, Closed Environment, Autonomous Navigation, OpenCV, Raspberry pi, Mobile Robot.

\section{PENDAHULUAN}

Dasar pemikiran yang menjadi landasan untuk penelitian ini adalah peningkatan kemajuan teknologi computer vision dalam bidang robotika. Kemajuan teknologi computer vision mengakibatkan dampak yang cukup signifikan dalam meningkatkan kemampuan dan kecerdasan robot. Pada suatu lingkungan tertutup (indoor) yang didalamnya terdapat objek-objek, robot diharuskan untuk bisa menghindari dan memilih jalur yang tepat.

Computer vision telah menjadi bagian penting dalam membangun robot cerdas pada masa mendatang. Robot membutuhkan informasi visi untuk memutuskan aksi apa yang akan dilakukan. Saat ini penerapan visi pada robot telah dapat ditemukan dalam berbagai bidang antara lain: bidang kelautan, bidang kedokteran, bidang militer dan lainnya. Visi pada robot menjadi sebuah informasi yang sangat penting karena menjadi data yang lebih detail dibandingkan jika hanya menggunakan sensor jarak atau sensor lainnya. Misalnya dengan visi, robot dapat mengenali apakah objek yang terdeteksi merupakan wajah orang atau bukan.

Proses pengolahan dari input citra dari kamera hingga dapat berguna bagi robot dikenal sebagai persepsi visual, dimulai dari akuisisi citra, prapemrosesan citra untuk memperoleh citra yang diinginkan dan bebas noise. Setelah diperoleh hasil citra yang lebih baik tahap berikutnya adalah dilakukan proses pendeteksian tepi dengan menggunakan metode Deteksi Tepi Canny.

Deteksi Tepi Canny mempunyai beberapa kriteria pendeteksi tepian paling optimum yaitu melokalisasi citra dengan baik, mendeteksi objek dengan baik dan respon yang jelas. Dengan kelebihan tersebut maka metode Deteksi Tepi Canny dapat menghasilkan gambar yang lebih representative sehingga mendekati objek sesungguhnya. Setelah proses deteksi tepi 
selesai maka langkah berikutnya adalah mengenali dan mengidentifikasi jalur ataupun halangan-halangan yang ada. Jalur dan halangan yang telah teridentifikasi akan digunakan sebagai model untuk menentukan kearah mana robot akan berjalan. Seluruh proses komputasi dan kontrol akan dilakukan dengan menggunakan Raspberry pi, sedangkan untuk pengolahan citra menggunakan aplikasi OpenCV.

OpenCV adalah sebuah aplikasi open source yang menyediakan library untuk pengembangan pemrosesan citra digital. OpenCV dapat dijalankan pada berbagai jenis platform, salah satunya adalah Linux. Hal inilah yang menjadi alasan dipilih raspberry pi sebagai kontroller robot. Raspberry pi dapat berjalan diatas sistem operasi berbasis linux yang dinamakan Raspibian. Selain itu raspberry juga memiliki konektifitas usb yang dapat langsung terhubung dengan kamera web. Demikian konsep dan penerapan vision pada robot dapat dikembangkan untuk membangun sistem robot yang berinovasi teknologi tinggi.

\section{Kajian Penelitian Sebelumnya}

Lasti Warasih H. (2008) dalam penelitiannya yang berjudul "Perancangan Mobile Robot Dengan Sensor Kamera Menggunakan Sistem Kendali Fuzzy" menyatakan bahwa algoritma sistem dengan penghalang masih kurang baik karena tidak mempertimbangkan ujung-ujung area yang ditangkap sensor kamera. Sistem sensor kamera yang digunakan sebagai umpan balik membutuhkan waktu cukup lama (sekitar $0,4 s)$.

Awaluddhin Choliq Azis, Widya Cahyadi dan Catur Suko Sarwono (2015) dalam penelitiannya yang berjudul "Aplikasi Tracking Object pada Sistem Web Streaming dengan Protokol TCP/IP sebagai Sistem Navigasi Mobile Robot Berbasis Mini PC' menyatakan secara keseluruhan sistem dapat berjalan dengan baik, pendeteksian obyek berhasil pada tingkat lumen cahaya sebesar $47.1 \mathrm{~lm}$ hingga $21500 \mathrm{~lm}$, pada rentang jarak deteksi baca 50 hingga $500 \mathrm{~cm}$.
Secara umum, sistem sensor kamera ini akan menangkap citra yang didalamnya terdapat beberapa objek yang berbeda, yaitu objek mobile robot dan objek penghalang, jika ada.

Maka pertama-tama ditentukan pola dari objek-objek yang akan dipakai pada sistem ini. Pola dari objek ini harus mempunyai ciriciri khusus yang untuk kemudian dapat menjadi ciri-ciri yang membedakan antar objek, dan juga dapat mempermudah sistem untuk mendapat informasi posisi dan sudut objek. Objek berbentuk segiempat yang dibagi menjadi sembilan bagian kecil (blok).
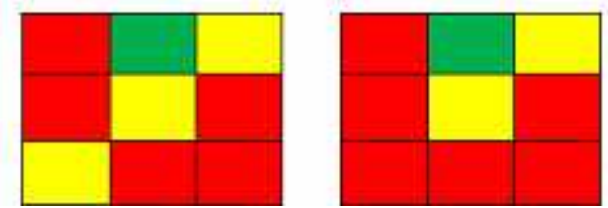

Gambar 1. Pola untuk identifikasi objek

Pada perancangan ini ditentukan dua pola yang digunakan pada sistem, dimana pola pertama untuk mobile robot dan pola kedua untuk objek penghalang.

Pemrosesan citra dilakukan pada PC dan terdiri dari tiga tahap yaitu pemrosesan citra awal untuk kepentingan perbaikan, pengambilan informasi objek untuk mendapat nilai posisi dan sudut, dan pengenalan objek untuk mengetahui identitas objek yang ditangkap. Proses ini secara lengkap digambarkan pada diagram alir yang ditunjukkan pada gambar 2 . 


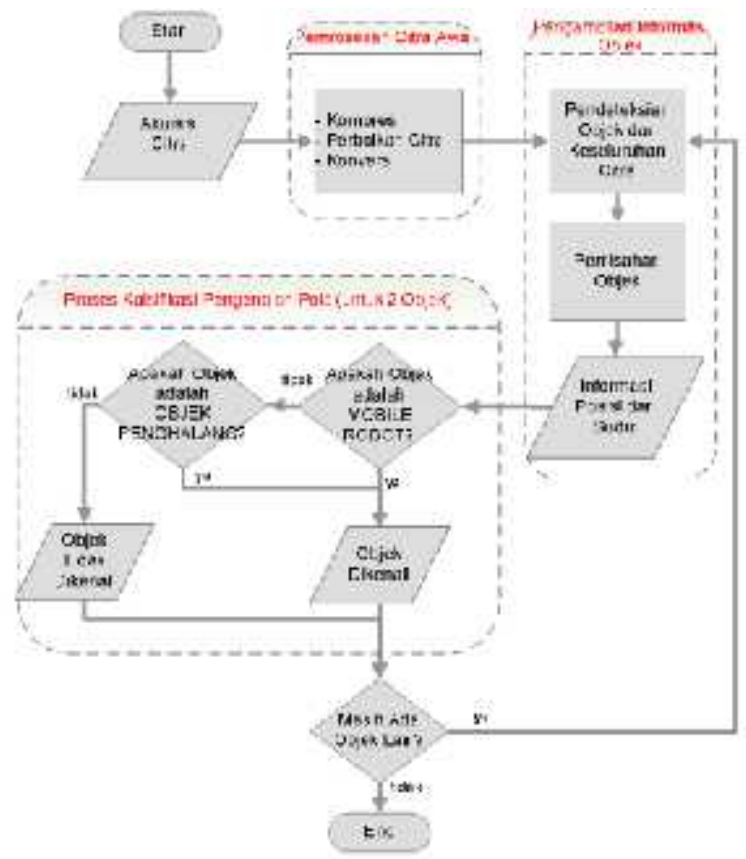

Gambar 2. Diagram alir sistem sensor kamera

\section{METODE PENELITIAN}

Desain sistem bertujuan untuk merancang kerangka penelitian bagaimana mengembangkan sistem vision pada Mobile Robot. Dalam proses pengembangan sistem dibutuhkan beberapa komponen utama meliputi kamera web, kontroler (raspberry pi) dan aktuator. Penekanan pembahasan dalam penelitian ini adalah pada kamera web dan raspberry sebagai unit pemrosesan citra. Secara umum perancangan sistem pemrosesan vision pada robot dapat dilihat pada gambar 3.

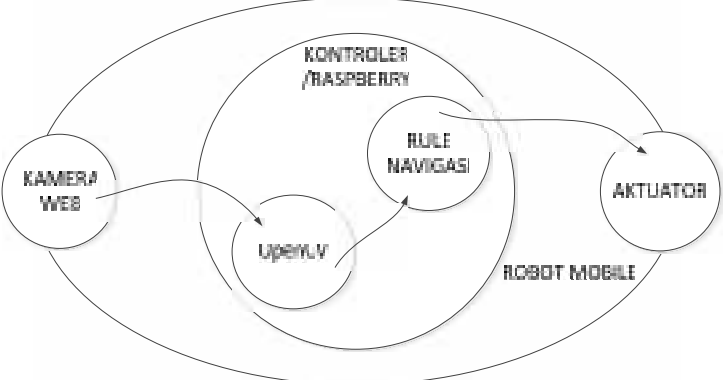

Gambar 3. Gambaran Umum Sistem Robot Gambar 3 menjelaskan hubungan antar komponen yang ada dalam sistem robot.
Kamera web berfungsi untuk mengakuisisi gambar dari lingkungan menjadi citra RGB. Setelah itu aplikasi OpenCV yang diinstalasi pada raspberry akan melakukan praproses gambar tadi untuk menghilangkan noise, agar dapat diproses dengan metode Deteksi Tepi Canny. Hasil dari proses Deteksi Tepi Canny kemudian akan dideteksi keberadaan jalur agar dapat menentukan rule navigasi robot.

Perancangan sistem untuk navigasi mobile robot berbasis kamera web dilakukan dengan menggunakan program openCV sebagai open source library dan Visual Studio 2012 sebagai IDE. Dalam tahap perancangan dan pengembangan sistem navigasi robot akan dilakukan di PC desktop dan juga mini PC secara bergantian. Pemrosesan sistem navigasi mobile robot secara umum ditunjukkan pada gambar 4.

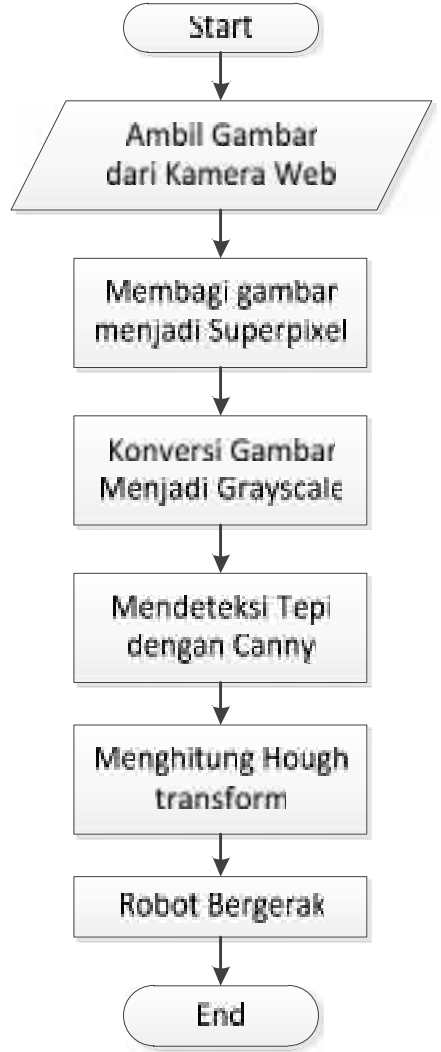

Gambar 4. Flowchat Sistem Navigasi Pada Robot

1. Mengambil citra gambar dari kamera web. 
2. Membagi gambar menjadi data superpixel.

3. Mengkonversi gambar RGB menjadi format grayscale

4. Menerapkan deteksi tepi canny

5. Menghitung Hough transform dari tepi gambar untuk menemukan garis horizontal yang dapat mewakili batas lantai.

Gambar yang diambil dari kamera mempunyai ukuran default yaitu berukuran 640x480 pixel. Untuk mendapatkan hasil yang akurat dibutuhkan ukuran pixel yang lebih tinggi serta pengelompokan nilai warna yang seragam atau mirip, sehingga gambar akan dibagi menjadi data superpixel. Setelah data dibagi menjadi superpixel selanjutnya dikonversi menjadi gambar dalam bentuk skala keabu-abuan (grayscale). Data dalam bentuk grayscale akan diproses dengan deteksi tepi canny untuk mendapatkan nilai dari tepi setiap obyek yang ada dalam gambar. Gambar yang dihasilkan setelah proses deteksi tepi canny akan diproses dengan Hough transform untuk menemukan garis horizontal yang mewakili garis batas lantai.

\section{HASIL DAN PEMBAHASAN}

\section{Implementasi Pengolahan Citra}

Proses pengolahan citra pada sistem navigasi robot dimulai dengan praproses. Tujuan utama dari praproses ini adalah untuk mengurangi noise-noise yang ada dalam gambar citra. Noise ini biasanya timbul dari pantulan-pantulan cahaya dari luar. Salah satu kelebihan dari openCV adalah sudah tersedia fungsi-fungsi untuk praproses maupun deteksi tepi canny. Fungsi yang digunakan untuk memanggil deteksi tepi canny adalah 'Canny(detected_edge, lowThreshold, lowThreshold*ratio, kernel_size). Sebelum proses deteksi tepi canny dilakukan filter untuk mereduksi noise.

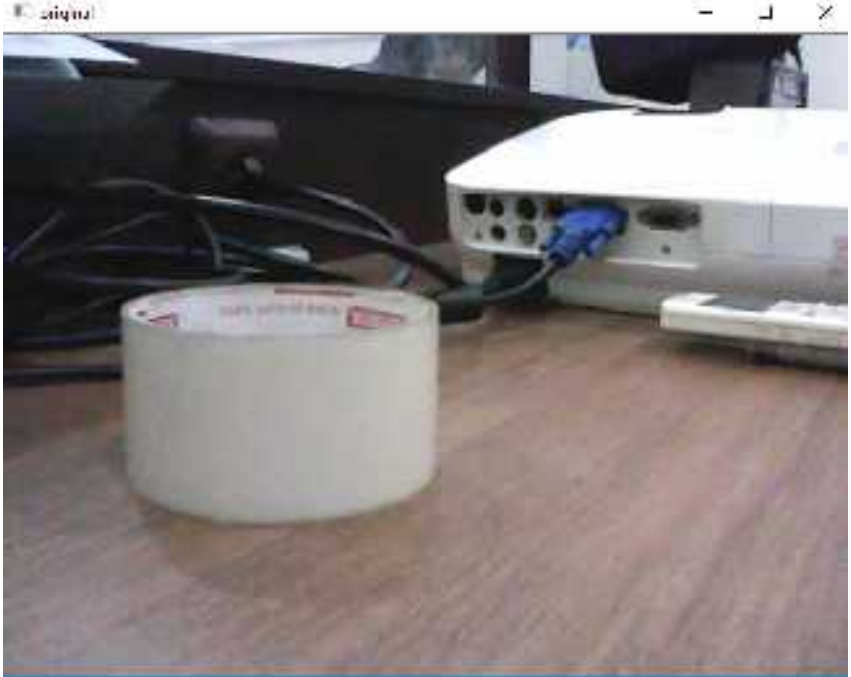

Gambar 5. Citra Awal Sebelum Proses

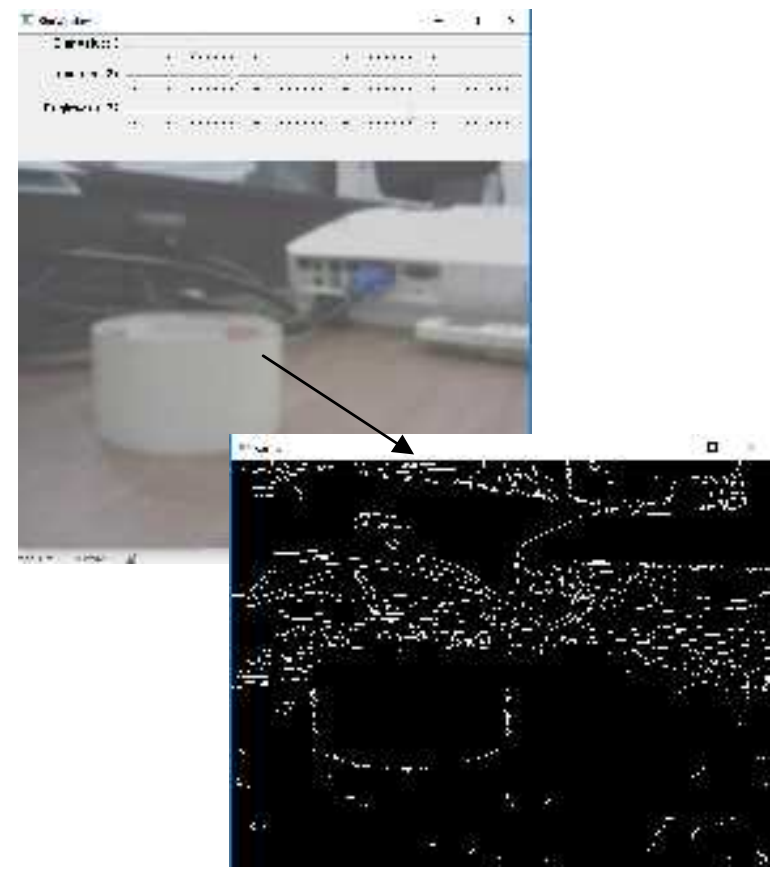

Gambar 6. Citra Setelah Deteksi Tepi Canny(1)

Gambar 6 menunjukkan hasil citra setelah dilakukan proses deteksi tepi canny. Parameter kalibrasi untuk data pada Gambar 6 adalah:

- Contrast : 27

- Brightness : 72

- Gausian Smooting : 8

- Batas atas Canny : 20 
- Batas bawah Canny : 3

- Jarak robot dengan obyek : $17 \mathrm{~cm}$ Untuk mendapatkan hasil deteksi tepi canny yang baik maka dilakukan uji coba parameter-parameter yang sesuai dengan kondisi cahaya pada ruangan.

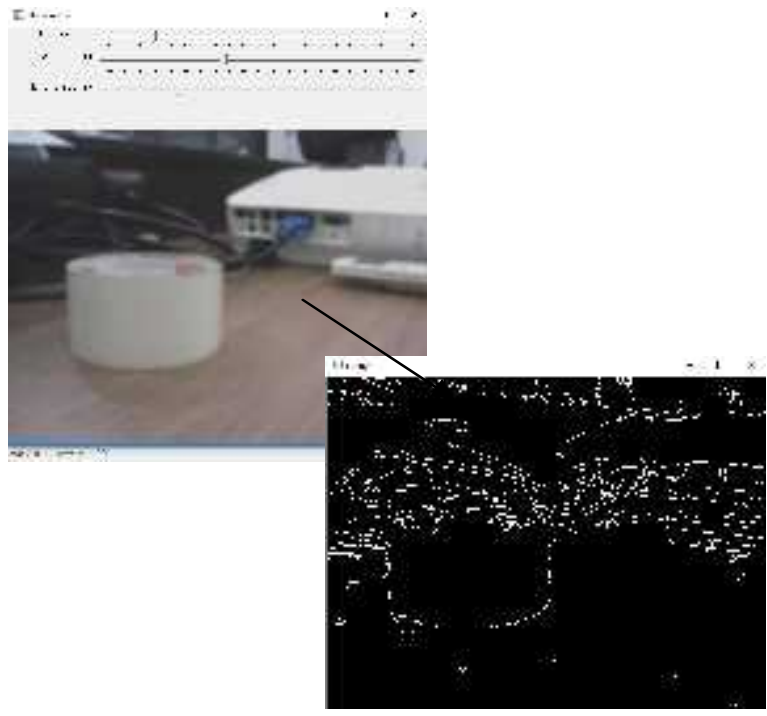

Gambar 7. Citra Setelah Deteksi Tepi Canny (2)

Pada gambar 7 dapat terlihat bahwa hasil kalibrasi proses deteksi tepi canny sudah lebih baik dengan parameter sebagai berikut:

- Contrast : 38

- Brightness : 24

- Gausian Smooting : 8

- Batas atas Canny : 32

- Batas bawah Canny : 3

- Jarak robot dengan obyek : $17 \mathrm{~cm}$

Hasil akhir sementara dari proses pengolahan citra ini adalah pada tahap hough transform. Proses hough transform dapat melakukan perhitungan citra dengan baik. Sehingga bisa dideteksi garis horizontal pada setiap daerah tepi.

Implementasi Mekanik Robot

Body robot secara keseluruhan terbuat dari bahan acrylic yang dibentuk menjadi bulat. Roda diletakkan pada masing-masing sisi samping termasuk juga driver motor dan rangkaian supply. Raspberry sebagai sistem pengolahan citra diletakkan pada sisi atas dari robot serta kamera web pada bagian depan robot. Hasil penerapan body robot ditujukkan pada gambar 8 .

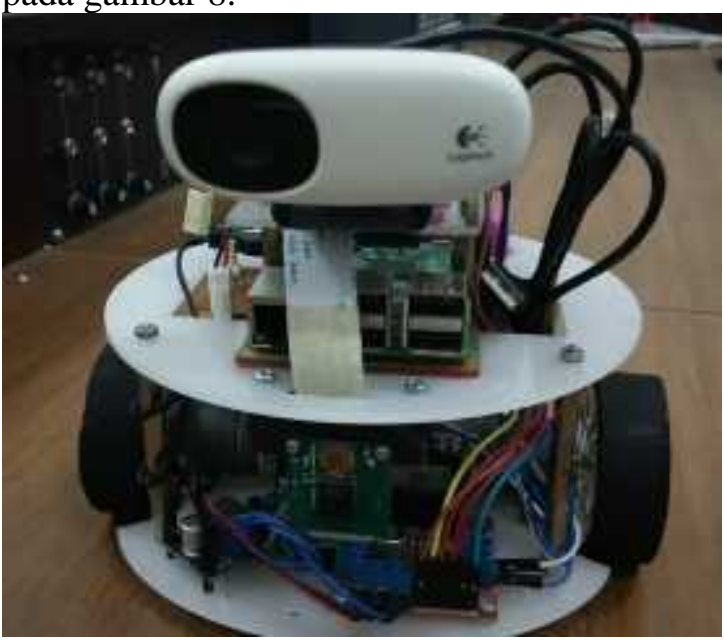

Gambar 8. Bentuk Robot Keseluruhan

\section{KESIMPULAN}

Setelah dilakukan proses pengujian maka didapatkan kesimpulan sebagai berikut: Deteksi tepi canny dapat diterapkan dengan baik karena dapat membatu robot untuk mendeteksi obyek yang ada. Pada kondisi ruangan dengan lantai tipe keramik glossy masih banyak mengalami gangguan akibat adanya pantulan obyek yang dideteksi.

\section{REFERENSI}

[1] Awaluddhin Choliq Azis, Widya Cahyadi, Catur Suko Sarwono, 2015, Aplikasi Tracking Object pada Sistem Web Streaming dengan Protokol TCP/IP sebagai Sistem Navigasi Mobile Robot Berbasis Mini PC, elektronik Jurnal Arus Elektro Indonesia, Universitas Jember

[2] Kukuh Darmawan Setyanto, Ike Fibriani, Sumardi, 2016, Pengendalian Mobile Robot Vision Menggunakan Webcam Pada Objek Arah Panah Berbasis Raspberry Pi, Jurnal Arus Elektro Indonesia, Universitas Jember

[3] Lasti Warasih H. , 2008, Perancangan Mobile Robot Dengan Sensor Kamera 
Menggunakan Sistem Kendali Fuzzy, Teknik Elektro Universitas Indonesia.

[4] Barcelo G.C, Panahandeh G, Jansson M, 2013, Image-Based Floor Segmentation in Visual Inertial Navigation, KTH Royal Institut of Technology. 